\title{
Measurement Methods for Evaluation of the Reliability of Active Implantable Medical Devices
}

NIST

Special

Publication 1047

\section{Report of a Workshop Held October 3-4, 2005}

Gaithersburg, Maryland

Elizabeth S. Drexler William F. Regnault John A. Tesk 
he National Institute of Standards and Technology was established in 1988 by Congress to "assist industry in the

development of technology ... needed to improve product quality, to modernize manufacturing processes, to ensure product reliability ... and to facilitate rapid commercialization ... of products based on new scientific discoveries."

NIST, originally founded as the National Bureau of Standards in 1901, works to strengthen U.S. industry's competitiveness; advance science and engineering; and improve public health, safety, and the environment. One of the agency's basic functions is to develop, maintain, and retain custody of the national standards of measurement, and provide the means and methods for comparing standards used in science, engineering, manufacturing, commerce, industry, and education with the standards adopted or recognized by the Federal Government.

As an agency of the U.S. Commerce Department's Technology Administration, NIST conducts basic and applied research in the physical sciences and engineering, and develops measurement techniques, test methods, standards, and related services. The Institute does generic and precompetitive work on new and advanced technologies. NIST's research facilities are located at Gaithersburg, MD 20899, and at Boulder, CO 80303. Major technical operating units and their principal activities are listed below. For more information visit the NIST Website at http://www.nist.gov, or contact the Publications and Program Inquiries Desk, 301-975-3058.

\section{Office of the Director}

-National Quality Program

-International and Academic Affairs

\section{Technology Services}

-Standards Services

-Technology Partnerships

-Measurement Services

-Information Services

-Weights and Measures

\section{Advanced Technology Program \\ -Economic Assessment \\ -Information Technology and Applications \\ -Chemistry and Life Sciences \\ -Electronics and Photonics Technology}

\section{Manufacturing Extension Partnership \\ Program \\ - Regional Programs \\ - National Programs \\ -Program Development}

\section{Electronics and Electrical Engineering} Laboratory

-Microelectronics

- Law Enforcement Standards

-Electricity

-Semiconductor Electronics

-Radio-Frequency Technology ${ }^{1}$

-Electromagnetic Technology ${ }^{1}$

Optoelectronics ${ }^{1}$

-Magnetic Technology ${ }^{1}$

\section{Materials Science and Engineering \\ Laboratory \\ -Intelligent Processing of Materials \\ - Ceramics \\ -Materials Reliability ${ }^{1}$ \\ -Polymers \\ -Metallurgy \\ -NIST Center for Neutron Research}

\author{
Chemical Science and Technology \\ Laboratory \\ -Biotechnology \\ -Process Measurements \\ -Surface and Microanalysis Science \\ -Physical and Chemical Properties ${ }^{2}$ \\ -Analytical Chemistry
-Atomic Physics
- Optical Technology
- Ionizing Radiation
-Time and Frequency ${ }^{1}$
'Quantum Physics ${ }^{1}$ \\ Physics Laboratory \\ -Electron and Optical Physics
}

\section{Manufacturing Engineering \\ Laboratory \\ -Precision Engineering \\ -Manufacturing Metrology \\ -Intelligent Systems \\ -Fabrication Technology \\ -Manufacturing Systems Integration}

\section{Building and Fire Research Laboratory \\ -Applied Economics \\ -Materials and Construction Research \\ -Building Environment \\ -Fire Research}

\section{Information Technology Laboratory}

-Mathematical and Computational Sciences ${ }^{2}$

-Advanced Network Technologies

-Computer Security

-Information Access

Convergent Information Systems

-Information Services and Computing

-Software Diagnostics and Conformance Testing

-Statistical Engineering 


\title{
Measurement Methods for Evaluation of the Reliability of Active Implantable Medical Devices
}

\section{Report of a Workshop Held October 3-4, 2005 Gaithersburg, Maryland}

\author{
Elizabeth S. Drexler \\ Materials Reliability Division \\ Materials Science and Engineering Laboratory \\ National Institute of Standards and Technology \\ Boulder, CO 80305 \\ William F. Regnault \\ Center for Devices and Radiological Health \\ Food and Drug Administration \\ Rockville, MD 20850 \\ John A. Tesk \\ Polymers Division \\ Materials Science and Engineering Laboratory \\ National Institute of Standards and Technology \\ Gaithersburg, MD 20899
}

May 2006

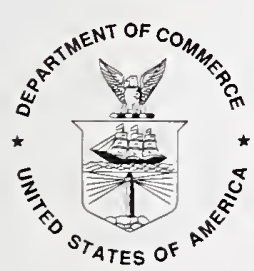

U.S. Department of Commerce

Carlos M. Gutierrez, Secretary

Technology Administration

Robert Cresanti, Under Secretary of Commerce for Technology

National Institute of Standards and Technology

William A. Jeffrey, Director 
Certain commercial entities, equipment, or materials may be identified in this document in order to describe an experimental procedure or concept adequately. Such identification is not intended to imply recommendation or endorsement by the National Institute of Standards and Technology, nor is it intended to imply that the entities, materials, or equipment are necessarily the best available for the purpose.

National Institute of Standards and Technology Special Publication 1047 Natl. Inst. Stand. Technol. Spec. Publ. 1047, 52 pages (May 2006) CODEN: NSPUE2

\section{U.S. GOVERNMENT PRINTING OFFICE WASHINGTON: 2006}

For sale by the Superintendent of Documents, U.S. Government Printing Office, Washington, DC 20402-9325 


\section{CONTENTS}

Executive summary.

Agenda

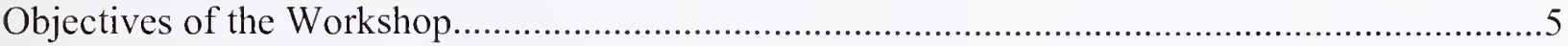

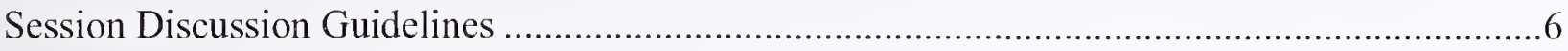

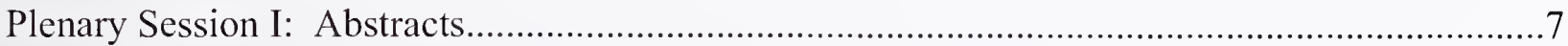

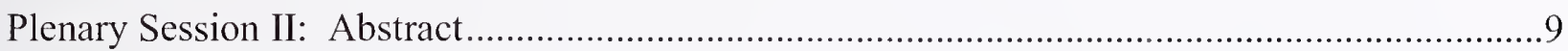

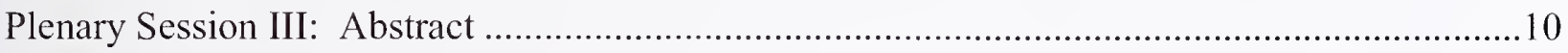

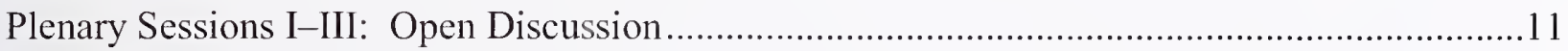

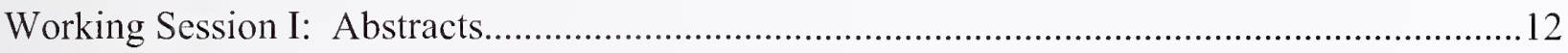

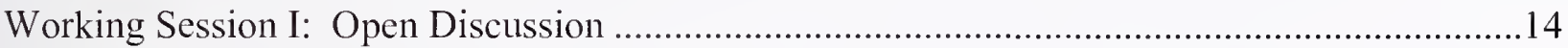

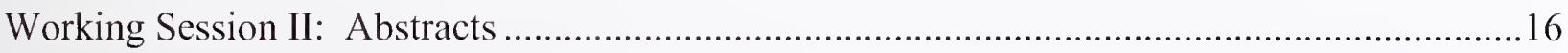

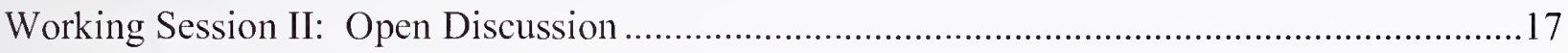

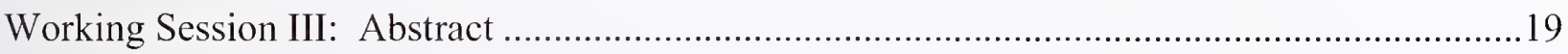

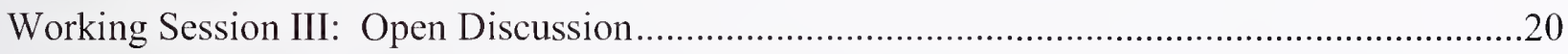

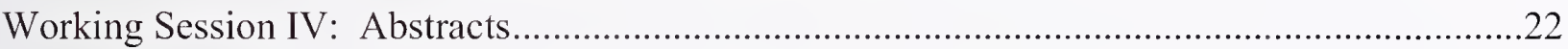

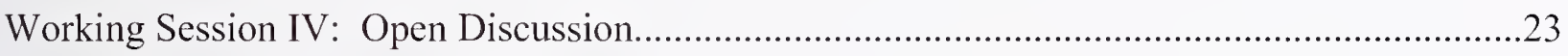

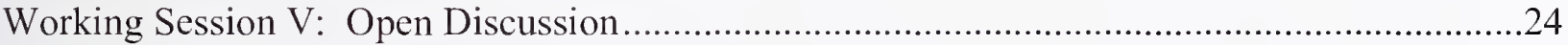

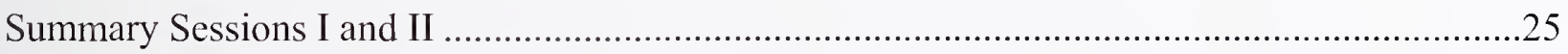

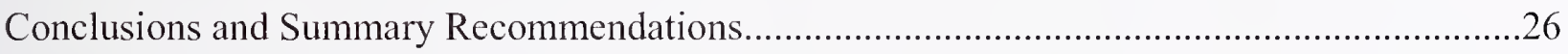

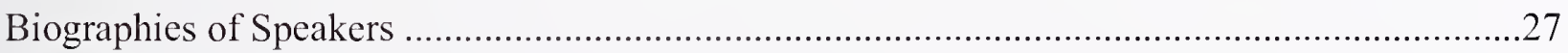

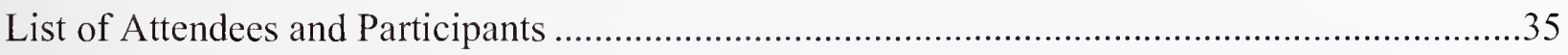

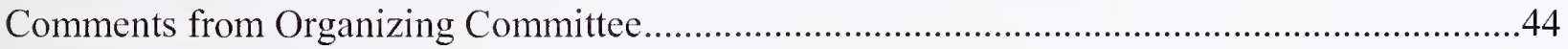

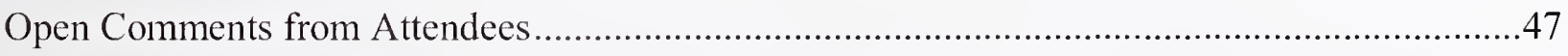

Appendix: $\mathrm{CD}$ of Presentations 


\section{Disclaimer}

The Notes from the Working Sessions included herein are as they were set down by our recorders. They were compiled during an open discussion with consensus from the group and as the discussion was interpreted by our recorders. Only misspellings and obvious misinterpretations of the spoken word have been corrected in this published version. 


\section{Executive Summary}

The US market for active implantable medical devices (AIMDs) was nearly $\$ 4.9$ billion annually in 2002 and is projected to more than double by 2007 due to aging demographics, product advances, and changing patient-care strategies, according to the 2003 report from the Freedonia Group, Inc. Recent recalls and publicized failures of active implanted medical devices have highlighted the need for improved device reliability and a more visible response by the device manufacturers to concerns of the American people and the Food and Drug Administration (FDA).

The workshop on Measurement Methods for Evaluation of AIMDs was held on October 3 and 4, 2005 in Gaithersburg, MD. The workshop was well attended, with 94 registrants. Fourteen device manufacturers were represented, 30 registrants were from the FDA, and eight were from the National Institute of Standards and Technology (NIST). The goal of the workshop was to help identify the technical and measurement issues that are involved in the use of both national and international standards for the assessment of the reliability of AIMDs, and to help define areas for future work that will facilitate the rapid deployment of advanced implant technologies. Specifically, the workshop sought answers to the following questions:

- How have manufacturing methods for active implantable medical devices changed over the past 20 to 25 years, and how have the sources and mechanisms for failure been affected?

- What are the conditions for assessing the overall reliability of a device? What else may be needed in addition to ISO 9000 ?

- How are end-point reliability measurement results for individual device components integrated into assessment of overall reliability; how should synergistic effects be assessed?

- What new measurement and analysis methods may be employed to improve assessment of reliability?

- Are there specific test methods that need to be developed for application to devices fabricated under different means?

- What is the relative importance of fabrication quality management vs. end product test measurements?

- How can government, academic, and industrial resources be applied most effectively in the development of medical device standards (e.g., development of measurement methods as a basis for standards, compilation of critical data as a basis for regulatory decisions, etc.)?

Plenary Session I opened the workshop with three speakers from the FDA, who discussed regulations, standards, and the patient's perspective. The following plenary sessions covered "designing for device reliability" and consensus standards. Since this was the first time that the AIMD companies all gathered under one roof, the agenda was set with experts in various aspects of reliability to kick off the discussions during the working sessions. Working Session I focused on plausible failure mechanisms inside the can, such as electronic and hermetic reliability issues. Corrosion and mechanical degradations of the can itself were the focus of Working Session II, to complete Day 1. On Day 2, the topic for Working Session III was choosing accelerators for predicting reliability and lifetimes. Engineers from two device manufacturers spoke during 
Working Session IV, one about designing for impact prior to implantation, and the other on reliability standards and practices, specific to their own companies.

For each Working Session the speakers were followed by a period of open discussion and questions to identify action items pertaining to the workshop goals. The open discussions covered a wide range of topics, the contents of which are provided in bullet format following the abstracts for the working session in this report.

Reliability issues that we inferred from the discussions during the working sessions are:

- The physical and chemical environment: does it change based on location in the body? What happens at the interface between biological and engineered materials?

- What are the mechanisms by which water accumulates within the can? Should improved test methods be developed to detect smaller leaks in smaller volumes?

- How do interfaces and electrical components respond to that moisture?

- Is it possible to modify or improve test standards to bring potential in vivo failure mechanisms to light? What, if any, are the appropriate accelerants for determining lifetimes?

- How should the use envelope be defined to account for the spectrum of physiques and activities of patients in whom the device will be implanted? How do parameters such as impacts, falls, torque, G forces, etc. affect the physics of the device in vivo?

- How do assembly, manufacturing, transportation, and storage stress the devices?

- Which animal models are appropriate for a particular system?

At the end of the second day, Working Session V: Reliability Issues for Future Devices, and Summarizing Working Sessions I-IV were held concurrently. The items discussed in those sessions are also provided in this volume in bullet format.

The speakers brought to the workshop a wealth of knowledge that is pertinent to AIMD. Outside (the industry) experts from universities, microelectronic powerhouses, and the military provided key insights into leak detection and residual gas content, corrosion, designing for and predicting reliability, microelectronic fabrication and reliability testing, and writing consensus standards. All agreed to participate in this workshop because they believe that designing reliable AIMDs is imperative, and they felt that they could contribute to that goal.

The workshop ended with the identification of some definite needs. These included the need for standard leak reference materials for leak rates three orders of magnitude lower than those currently available, validated test methods for measuring such leak rates, and models for calculating leaks rates from flaws of various geometrical and material combinations at the design stage and for helping validate leak rate measurements on a reliably repeatable basis.

It was agreed that one or more follow-up workshops are desired. However, the size, topic and format of that (those) workshop(s) should be determined by a planning committee that includes representatives from the FDA, NIST, and the AIMD Industry. Further input is sought from interested parties and should be conveyed to Elizabeth Drexler at NIST (Drexler@boulder.nist.gov). 
OCTOBER 3, DAY 1

8:00 a.m. Registration \& Continental Breakfast

8:55 a.m. Introductions, Moderator, John A. Tesk

9:00 a.m. Welcome to the Workshop, NIST \& the FDA

9:10 a.m. NIST \& Biomaterials

9:20 a.m. Introduction to the Workshop Issues

Rich Kayser NIST

Lori Henderson NIST

William F. Regnault FDA

Plenary Sessions I, II \& III Moderator, William F. Regnault, FDA

\section{9:35 a.m. Plenary Session I}

9:35 a.m. Patient Perceptions Leading to Explantation

10:00 a.m. Post-Market Regulation of Medical Devices

10:25 a.m. GMP Regulations and Standards

10:45 a.m. BREAK

11:00 a.m. Plenary Session II-Designing for Intended Use and Reliability Ali Mosleh U MD 11:30 a.m. Plenary Session III-MIL-STDS and Consensus Standards: Their Utility and their Inference for Device Reliability

11:30 a.m. What Standards are Needed?

James Kane FDA

Betty Collins FDA

Jan Welch FDA

12:00 a.m. Issues Surrounding the Use of Standards and Test Methods: Open Discussion

12:30 p.m.Lunch, NIST Cafeteria

Working Sessions I \& II Moderator, Elizabeth S. Drexler, NIST

1:30 p.m. Working Session I-Plausible Mechanisms for Failure: Mechanisms Inside the Can Session Chair: Jack Martinez

NIST

1:30 p.m. Chip-Level Design: Developments, Failure Mechanisms and Reliability Testing

Ken Rodbell IBM

1:50 p.m. Package-Level Design: Developments, Failure Mechanisms and Reliability Testing

2:10 p.m. Residual Gas Content and Ionic Content

Robert Munroe (Retired) Motorola

2:30 p.m. Answers for Advice that the Workshop Seeks (see Session Chair's Guide)

3:30 p.m. BREAK

3:45 p.m. Working Session II-Plausible Mechanisms for Failure: Mechanisms Outside the Can

Session Chair: Michael Schen

NIST

3:45 p.m. Corrosion Issues

4:05 p.m. Impact, Trauma, and Vibration Issues

Robert Baboian RB Corrosion Service

4:25 p.m. Answers for Advice that the Workshop Seeks (see Session Chair's Guide)

5:25 p.m. End of Day 1

OCTOBER 4, DAY 2

7:45 a.m. Registration \& Continental Breakfast

Working Sessions III \& IV Moderators, Elizabeth Drexler, NIST \& John Tesk

8:45 a.m. Working Session III-Measurements for Accelerated Reliability Testing of Packages Session Chair: Stan Purwin Johns Hopkins University Applied Physics Laboratory

8:45 a.m. What are the Proper Accelerators for Predicting the Reliability of Active Implantable

Medical Devices?

Michael G. Pecht UMD 
9:05 a.m. Answers for Advice that the Workshop Seeks (see Session Chair's Guide) 10:05 a.m. BREAK

10:20 a.m. Working Session IV_-Medical System Concerns- Manufacturers' Perspectives Session Chair: Keith McLain Advanced Bionics Inc. 10:20 a.m. Medical System Concerns-Manufacturers' Perspective David Erhart Medtronic 10:40 a.m. Cochlear Ltd. Internal Reliability Standards and Practices

Edmond Capcelea Cochlear Corporation 11:00 a.m. Answers for Advice that the Workshop Seeks (see Session Chair's Guide) 12:00 p.m.Lunch, NIST Cafeteria

1:00 p.m. Drafting of Workshop Sessions I, II, III \& IV Summaries

(Dining Room B: Session I, J. Martinez, K. Rodbell, R.Munroe, B.Thomas; Session II, M. Schen, R. Baboian, D. Hammerer)

(Room A149, Bldg 224, Polymers: Session III, S. Prrwin, M. Pecht; Session IV, K. McLain,D.Erhart, E. Capcelea)

1:00 p.m. Working Session V-Reliability Issues for Future Devices,

Session Chair: John Suehle

Moderator, Elizabeth Drexler NIST NIST

(Session $V$ is open to all except the previous session chairs and presenters from those sessions who wish to work with their session chairs on developing Summary Recommendations)

2:15 p.m. Conclusion and Summary Recommendations Moderator, W. F. Regnault, FDA

Who is to do what?

Where is the work to be done?

How is the work to be accomplished?

Is there a need for a follow-up workshop or symposium?

3:00 p.m. End of Workshop

\section{Planning Committee}

William F. Regnanlt,.........Center for Devices and Radiological Health, FDA \& Griest Researcher, NIST

Elizabeth S. Drexler, ..........Materials Reliability Division, NIST

John A. Tesk,................ Consultant \& Guest Researcher, NIST

Michael Schen, .............. Advanced Technology Program, NIST

Workshop Scribes

Tonya Icenogle, ...............Center for Devices and Radiological Health, FDA \& Guest Researcher, NIST

Tithi Dutta Roy, ..............Postdoctoral Fellow, Biomaterials Gronp, Polymers Division, NIST 


\section{Purpose:}

To help identify the technical and measurement issues that are involved in the use of both national and international standards for the assessment of the reliability of active implantable medical devices, and to help define the areas for future work that will facilitate the rapid deployment of advanced implant technologies.

\section{Topics:}

The workshop seeks insight to answers for the following questions:

- How have manufacturing methods for active implantable medical devices changed over the past $\mathbf{2 0}$ to $\mathbf{2 5}$ years, and how have the sources for failure mechanisms been affected?

- What are the conditions for assessing the overall reliability of a device? What else may be needed in addition to ISO 9000 ?

- How are end-point reliability measurement results for individual device components integrated into assessment of overall reliability; how should synergistic effects be assessed?

-What new measurement and analysis methods may be employed to improve assessment of reliability?

- Are there specific test methods that need to be developed for application to devices fabricated under different means?

- What is the relative importance of fabrication quality management vs. end product test measurements?

- How can government, academic, and industrial resources be applied most effectively in the development of medical device standards (e.g., development of measurement methods as a basis for standards, compilation of critical data as a basis for regulatory decisions, etc.)? 


\section{Session Discussion Guidelines}

This guide provides suggestions to help participants:

1. Engage in the discussion of each session,

2. Reach conclusions and,

3. Identify action items (It is essential that your session reach this stage in order to bring the workshop to a successful conclusion).

\section{Please consider the following:}

1. Develop a list of Critical Needs

2. Identify whether the Need is:

a. A consensus standard

b. A standardized test method

c. A standard practice (e.g., manufacturing measurement or process control, data analysis)

d. A guidance document on the use of existing standards and practices

e. Anything else (e.g., fundamental research, measurement development)

3. Identify why each Need is considered important

Examples:

a. Improvement of an existing device component

b. Improvement of fabrication technology

c. Submission of a new device for FDA approval

d. Understanding of device-tissue and device-patient interactions

f. Uniformity of industrial practices (e.g., sampling, assembly, cleaning, tolerance control)

g. Standardization of measurement technology

h. Improvement of measurement technology (calibration, instrumentation, etc.)

i. Support for measurement science needs development

j. Reduction of barriers to trade

k. Harmonization of development of standards for national and international uses

1. Application to other regulatory purposes (GMP?)

4. Prioritize the Needs as to their importance

5. Provide Rationale for the Prioritization

6. Identify how each Need should be approached to resolve its critical issues: thorough participation on a standards committee at a national or international level, by collaboration with other stakeholders (e.g., round robin testing, test method development, process measurement or development, fundamental research etc?)

The Session Chair will use the discussions to develop a summary report

The report should identify (if possible):

a. Who is to do WHAT? (The participants and organizations that must be involved, etc.)

b. The action needed to initiate the work on each item

c. Who is best qualified to take the lead 


\section{Plenary Session I: Abstracts}

\section{Patient Perceptions Leading to Explantation (Cochlear Implants) \\ James K. Kane, Ph.D.}

The three cochlear implant manufacturers who have received marketing approval from FDA currently report similar cumulative survivability rates (CSR) per ISO 5841-2, rev. 2000 (reliability standard used by the cardiac pacemaker industry). Notably, however, two of the three manufacturers had device problems in 2004 sufficient to voluntarily initiate device recall from the U.S. market and, for one manufacturer, a world-wide recall. Assuming data integrity is not an issue, and recognizing that the CSR reflects only device explants over time (necessarily ignoring ongoing functionality problems) perhaps the CSR, in and of itself, is not a sufficient metric for illuminating device problems to the public, to potential users of the device, or to the FDA.

Within the cochlear implant device industry, as well as within the cochlear implant clinical community, efforts are underway to relate patients' unusual perceptual/behavioral reports to device functionality. Such reports frequently are suggestive of device malfunction prior to complete device failure and commonly are referred to as "soft" failures. These clinical symptoms often occur even though an implant may pass the manufacturer's in situ device integrity tests. This presentation will overview this subject area with supporting data obtained from implant manufacturers' complaint files during the past year.

\section{Post-Market Regulation of Medical Devices Betty Collins}

Medical devices include thousands of health products, from simple products such as latex gloves to sophisticated robotic systems for laser surgery. The manufacturers of medical devices that have been cleared or approved for distribution in the United States are routinely inspected to ensure that they are safe and effective for their intended uses. Thus products go from a premarket review to "post-market" surveillance. Post-market activities play a critical role in consumer protection. During post market surveillance, the Office of Compliance looks at a number of areas that provide meaningful and important indicators (signals) of a firm's compliance with regulatory requirements. A discussion on some of these signals and their importance in complying with post-market regulation will be covered.

The Relationship of Standards and Compliance with the Quality System Regulation from an FDA Perspective Jan Welch

This presentation will provide the audience with an understanding of how the FDA uses standards and guidance documents in assessing medical device manufacturers' compliance with the Quality System (QS) regulation. The presentation will focus primarily on post-market activities associated with ensuring compliance with the QS regulation, but the role of standards 
in pre-market activities will be briefly mentioned to highlight the important relationship between these sets of activities.

This presentation will focus particularly on those major quality system subsystems where FDA notes significant use of standards by manufacturers. This includes a discussion of the use of standards within the design control subsystem, the production and process control subsystem, and the corrective and preventive action subsystem. The presentation will also include a brief discussion of FDA's inspectional approach to the use of standards. 


\section{Plenary Session II: Abstract}

Estimating Reliability at Design

Ali Mosleh

How are end-point reliability measurement results for individual device components integrated into assessment of overall reliability; how should synergistic effects be assessed? What new measurement and analysis methods may be employed to improve assessment of reliability? These questions and more will be answered as I explore techniques for assessing reliability. 


\section{Plenary Session III: Abstract}

\section{The Value Proposition for Medical Grade Components}

Celeste Null

Monolithic and hybrid electronic silicon components have routinely been incorporated into medical devices over the last forty years. Unfortunately, many of these components are taken from distributor shelves or developed internally and their reliability validated by outdated and improper military specifications because the industry has lacked appropriate standards for medical components. Failure mechanisms may or may not accurately reflect usage envelopes. Common stress tests shall be confronted, as well as review of the challenges that face both semiconductor and medical industries as growing incorporation of electronic devices and wireless connectivity occurs globally in medical devices. A call to action for development of medical grade component standards is offered. 


\section{Plenary Sessions I-III: Open Discussion}

\section{CRITICAL NEEDS}

- Manufacturers need to provide requirements without having all of the facts on the biomedical devices

- Medical companies outsourcing components (made by companies that aren't just providing components for the biomedical industry)

- How do you check the companies' specifications?

- Companies repackage circuits from large companies (Intel for example) for military and biomedical uses

- Radiation testing for implantable devices

- Use master files to protect confidentiality

- Understanding about what causes device failure

- Mechanical failure, not necessarily electrical components

- Liability issues

- Specification to screen commercial components (up-screening)

- Higher volume commercial parts more reliable, smaller companies have good screening processes

- Building quality parts, preferred to screening (expensive)

- Fault grade requirements

- Place to publish adverse events

- Establishing communication with foundries and suppliers, partnership (two-way communication)

- Designer needs to understand the use of parts, constant changes in technology, integration of components into a system (systems engineering)

- Verification and validation of systems

- Assessment of reliability verses improvement (redesign)

\section{IMPLANTABLE DEVICE COMPONENTS}

- MEMS

- Optical components

- Where are the vulnerabilities of the components in the system? 


\section{Working Session I: Abstracts}

\section{Chip-Level Design Developments, Failure Mechanisms and Reliability Testing Ken Rodbell}

In this talk the modern silicon-based integrated circuit (IC) will be discussed from two main perspectives - relevant failure mechanisms and reliability testing. A brief overview of chip level design will also be considered in light of these failure mechanisms and recent novel materials and structures that are being proposed for use. The following reliability issues will be highlighted, with some recent examples of a small subset of these explored in greater detail (as time allows).

- $\quad$ Negative bias temperature instability

- $\quad$ Soft error rate (radiation induced)

- $\quad$ Silicide defects

- Metal interconnect

Electromigration

Stress

Package-Level Design Developments: Failure Mechanisms and Reliability Testing Robert A. Munroe

In today's technologies the most frequent causes of reliability failures in service, in my experience, fall into three categories. One category is failures that are induced in manufacturing of the components or assembly and are not detected in routine testing. A second category is failures due to suppliers changing processes or materials without notification to customers despite the standard clauses prohibiting these changes. A third category of failures is the result of using cutting edge technology without sufficient experience with that technology.

Furthermore, close monitoring of incoming components and materials and frequent sample stress testing or detailed assembly analyses is often reduced or eliminated to minimize costs of products. Examples will be given for approaches (to new technology) that encompass that technology and minimize risk.

Reliability testing for new products is often menu driven from history or tradition and may not apply to the particular product being designed. The manufacturer is often reluctant to vary from "standard" tests. The "standard" tests may be too harsh or not harsh enough for the application intended. They may not test for the environment or reveal the failure mechanisms to which a new technology or product may be susceptible. Following the philosophy of Dorian Shainin (a peer of Deming and Graham), few manufacturers ever verify their qualification assumptions to validate them or find unexpected failure mechanisms. Shainin suggested examining products in the application when it has not failed; it is through the examination of such in-service products over time that unanticipated mechanisms can be revealed. (Testing for failure ensures that you will get the expected failure mechanism.) With medical implants this may have to be done with animals, if the appropriate model exists, but it should be done at increasing periods of time to be able to detect unexpected results and make corrections and recalls before failures exhibit themselves in the field. 


\section{Residual Gas Content and Ionic Content \\ Bob Thomas}

This presentation will discuss the origin of the RGA measurement technique and the problems in getting industry to adopt MIL-STD 883, Test Method 1018. Examples of the positive effect the Test Method had on both industrial and military packages will be discussed, and the methods companies tried in order to avoid using the method. Efforts at contamination control will be presented including the photos from the human spittle experiments that are still relevant to the medical implant field. Finally, a summary of the current implant technology will be reviewed from a perspective of moisture and contamination control. 


\section{Working Session I: Open Discussion}

\section{IDEAS}

- Standards and test methods from companies should be shared, respecting confidentiality - Needed for device implants

- Need a good interface model, and need to define parameters

- Confidential task force to share ideas among the experts in the field

- Is Dauskardt from Stanford an appropriate expert?

- How would you fund task force? NIST? Semiconductor International Association? (protected data)

\section{DISCUSSION}

- No incentive to share processes with other companies

- Develop the right tools (Military Standard might be out of date)

- STACK International (London, England)

- GIDEP-publish failures in the field that people experience

- Develop a networking connection guide for the Medical Implant Device community - Website

- JEDEC - standards, problems associated with standards

- Need the data to show the problems and failure rates, but without names of companies and associations

- Can we use standards to predict failures that we are going to see?

- AIME - leads failures, ISO tag international standard for active implants

- ASTM or SEMI

- To what extent does design affect the failure

- Intermediate ranges are not understood in terms of humidity, for example

- Synergistic effects from environment

- Measuring hermeticity - leak model without ideal gas law, (need support from industry for NIST to pursue this issue)

- Build device that will operate at saturation

- FDA to figure out how to sanitize data

- Ultimately it needs to be the FDA that instigates standards development

\section{NARROWING DISCUSSION}

- Data

- Regulatory perspective

- FDA interaction with component suppliers

- Current failure modes

- Future failure modes

- Need a group to develop these areas: FDA, NIST, medical device people, and component suppliers

- What are the future trends in packaging?

- Development of cochlear standard in Europe (good model) 


\section{INSPECTIONS}

- Need expertise to ask the right questions

- Get involved with the people who are doing the auditing

- How do you gain the subject matter experts?

- Who is going to participate and why? How will it be funded? 


\section{Working Session II: Abstracts}

Corrosion Issues

Robert Baboian

Corrosion is one of the most important factors in the reliability of active implantable medical devices. The environment to which these devices are subjected is severely aggressive. In addition, even very little contamination in electronic components can cause failure. Therefore, proper design and relevant testing of those designs are required to insure reliability. This talk includes discussions on types and mechanisms of corrosion in electronics devices, and, descriptions of tests that are used to determine the corrosion resistance of these devices. The applicability of these tests and the need for new tests for active implantable medical devices will be included in the talk.

Impact, Trauma, and Vibration Issues: Mechanical Loading of Active Implantable Medical Devices

Dominik Hammerer

Active implantable medical devices that are exposed to vibration, crush and/or impact/shock may fail in a variety of manners (e.g., detachment of single electronic components from the circuit board, collapse of the hermetic implant package), thus potentially rendering the device partially or entirely nonfunctional. Severity of these mechanical loading scenarios is dependent on the specific root cause. Situations including device shipping, handling prior to implantation, everyday life, and random events such as severe accidents, will be addressed. Further, it will be presented how the type of medical implant and its specific location of implantation influence the stress that the device undergoes.

Based on experiences with design, development, manufacturing and field performance of cochlear implants, standards applicable to these foreseeable loading scenarios, if available, and experiences with their implementation will be examined. Based on practical examples, (e.g., accident-related impacts to the device) methods of approaching un- or under-defined testing requirements, and therefore related difficulties, will be used to define previously unaddressed critical needs. 


\section{Working Session II: Open Discussion}

\section{DISCUSSION}

- What are the types of corrosion that are important?

- Metal, glass, plastic, etc.

- Internal vs. external

- Simulation of liquid composition

- Can these tests be used to determine reliability?

- Could use the temperature stress test to determine hermeticity

- Tests for conventional electronics, not implants

- With time the resistance will go up until failure, test in class II environment, one day of testing equals one year

- Environments in class IV are in chemical factory

\section{CORROSION}

- For external surface of an electronic device in the in vivo environment there is no acceleration test for corrosion

- For testing electrode

- Increase duty cycle, increase temperature (perhaps precipitation)

- Point: aerospace applications are not appropriate for these devices (active medical implants)

- Hermeticity breach can cause corrosion

- Corrosion, residual moisture inside the package

- Do we need acceptable levels of contaminates? moisture? gases? ionic contamination?

- Impact of tissue capsule around implants, stationary electrochemistry of corrosion

- Dynamic polarization test, run for each metal, mixed potential theory; coupled metals are very complex and difficult to understand

\section{EXTERNAL CORROSION}

- What are the issues?

- Strain from cardiac fatigue cycle (stents)

- Impact and shock vibration?

- Temperature chip, measures impact and shock

- What do you need to know about the environment to redesign implanted devices?

- Interface between the materials and body is problematic, there are no good ways to simulate human interface (biological environment)

- Understanding duty cycle and the tissue encapsulation at the interface with the medical device (chemically)

- Design for 20 years and test for 10 


\section{UNDERSTANDING THE ENVIRONMENT}

- Lack product specific information

- Specifics of location of implant in the body

- Many variables on determining the response of an implant to an impact (mass of device, surface area of device, tissue around the device, etc.)

- Deficiency in standards, 6601

- We need to define the use envelopes

- Need extreme models

- Proposed model for the head

- Is there a need for a body phantom?

- To simulate loading in the body for implanted devices 


\section{Working Session III: Abstract}

What are the Proper Accelerators for Predicting the Reliability of Active Implantable Devices? Michael Pecht

Active implantable devices must operate reliably, often as long as 10 years, while subjected to in vivo and external loading conditions. While implant reliability requirements will depend upon the target application, the reliability requirements are usually coupled with the need for minimal or zero maintenance.

This presentation overviews some of the issues with the reliability prediction of medical electronic devices, summarizes failure mechanisms that are of unique concern in implantable active devices, and discusses some life cycle approaches to assess implant reliability at the levels of device, packaging, power supply, and software. Methods reviewed cover accelerated testing for product qualification, manufacturing process qualification to eliminate design and manufacturing defects, and procedures for the detection of latent damage. 


\section{Working Session IIII: Open Discussion}

\section{FAILURE MECHANISMS}

- Unique by part type, failure mechanism

- May determine a common set of tests for a specific group

- Sharing of failure modes for devices over time (need more publications in this area)

- Knowing the failure mechanism will help you determine the best test method for qualification parameters

- Start with MIL-STD 883 then modify testing based on failure mechanism

- Failure mechanism-moisture breaching interface and depositing water on the chips

- Desire to use encapsulants, not going to take implants out of hermetic packages (can) for a long time

- Test the severe, covering all the ranges, but the limits may not be observed in reality (screening qualification process wears out the parts)

- Start looking at materials that are nearly hermetic

- Characterize new die lots and any other changes by the suppliers

- Trailing edge circuits (usually customized chips)

- Reliability of the microprocessors

- Realize that surgeons are important part of the implantable device (form factor), and familiarity with the insertion and size of the device (iimited by surgical tools)

\section{DISCUSSION 1}

- Improved functionality and longevity (desires of most clinicians)

- Reducing the size of device: battery is limiting factor, as is the ability to manufacture it reliably(?)

- Is current density a limiting factor?

- New technology development (artificial pancreas, drug delivery and sensor)

- Need to consider interface with biological devices and electronics

\section{TESTING METHODS}

- What is the testing methodology for the cans as they get smaller?

- Perhaps the FDA could raise this as an issue, helium leak jet for example

- Different failure mechanisms due to changes in the device over time, not appropriate to have a common test method

- Water in a can is a universal problem

- Statistically high moisture failure over $95 \%$ of devices could be attributed to hermeticity

- Need help modeling leaks for less than $10^{-9} \mathrm{~atm}-\mathrm{cc} / \mathrm{sec}$

- Leak detectors 


\section{STANDARDS}

- Military standard given package size and given leak rate

- Medical, use only to develop test method

- Equations based on ideal gas law, need to change the model, surface migration, and need to determine the leak structure

- All materials leak; it's just the rate of leak that is the issue, can't measure very small leak rates

- How do you measure small leak rates and examine the physics of the leak?

\section{MOISTURE}

- Sometimes moisture develops through chemical interaction in the materials

- Water is bound on the surface and moves around, so volume-to-surface area ratio is important

- Time period of implantation determines the moisture failures, $\sim 6$ to $7 \%$ fail in 4 to 5 years

- Are there failures in the screen? Destroy about $5 \%$ of product by handling

- 883 offers both screen and qualification

- Diffusion and leaks lead to moisture

\section{DISCUSSION 2}

- Develop a database for copyrighted materials without violating the law

- OVID - information sharing group, pay a fee and can download papers from IEEE

- Test functionality on older plastic samples that didn't fail, epoxy sustained over time

- Get a policy in place to get devices that are explanted to study

- How do you fund implant retrieval program? 


\section{Medical System Concerns - A Device Manufacturer's Perspective \\ David L. Erhart}

Assuring the highest practical reliability is a primary objective of any active implantable medical device manufacturer. In order to accomplish this objective the device manufacturer must understand and characterize the intrinsic and extrinsic reliability of the medical device. The basic material choices and design rule implementations that determine intrinsic reliability must be studied carefully and completely. The assessment of intrinsic reliability should be performed as early as possible during the development of a new product so material and design changes may be made with a minimal impact on the process of new product development. In this presentation, an example of an early opportunity for intrinsic reliability evaluation is examined. Through the example of device- and hybrid-level drop testing, the challenges of mapping incompletely defined application requirements onto a repeatable and meaningful test protocol will be highlighted. These challenges will be generalized to reflect the full range of active implantable medical device application requirements. The opportunities for improvements in application requirements and testing methodologies will be summarized.

Self-Imposed Standards and Requirements for Demonstrating Safety and Reliability:

A Device Manufacturer's Perspective Edmond Capcelea

The implantable medical device industry has been an intensely regulated market, given obvious considerations such as safety and effectiveness. Different regulatory bodies generally stipulate different requirements for and approaches to the approval process, although more recently attempts have been made to integrate, or align to, a common set of generic requirements. In addition to this, in many cases flexibility has been built in to the regulatory requirements to allow unimpeded development of new devices while maintaining high standards of safety and effectiveness. In some cases, according to this principle, the manufacturers are allowed to define the low-level set of requirements that will demonstrate the safety and effectiveness of the implantable device, providing that they strictly adhere to the high-level requirements set forward by the regulatory body. This presentation is focused on describing the set of self-adhered standards and/or self-defined requirements that were employed by Cochlear Ltd to demonstrate the safety and reliability of its new implant developments, starting with wafer-level requirements for ASIC developments, assembly requirements and finally system-level requirements. 


\section{Working Session IV: Open Discussion}

\section{DISCUSSION}

- Intrinsic and extrinsic factors

- Need for process design or validation

- Delamination not correlated to functional failures

- Studies on reproducibility of testing for characterization

- MIL-STD testing $\sim \$ 100,000$

- Save money by defining use envelopes

- Important to look at ASIC standard testing, but there's no good standard for testing in medical device industry

- Standards (for example MIL-STD 1031) are good for a minimal set of requirements

- How do we get meaning from these tests?

- Meta analysis of the medical device literature

- Patient issues for spinal cord device lead breakage (mechanical failure), battery depletion

- Need to continue researching the basic science with a foundation in physics (model for all failures that will reflect back to the design of the devices)

- How do we get the FDA and NIST to help the medical device industry?

- Providing a list of priorities from the industry

- Devices that need the greatest help with reliability

- Infusion pumps, defibrillators, ventilators

- Workshops in the future

- Smaller or bigger

- More input 


\section{Working Session V: Open Discussion}

\section{DISCUSSION}

- Standards for mechanical testing of flexible substrates

- Avoid using off-the-shelf consumer electronics

- Choice of vendors

- Passive vs. active components

- Developing screening for parts

- Standard tests for in vitro testing

- Understanding key parameters

- Looking towards other industries for material selection

- Dental industry

- Encapsulation of devices with fibrous tissue - mechanical issues

- Contraction of fibrous tissue around implant

- EN 45502 - Fatigue test for pacing leads

- New polymers and testing

- Life expectancy, etc.

- Buddy Ratner - University of Washington

- Polymer Technology Group - Berkeley, CA

- Biomaterials Group, Polymers Division, NIST

- Materials Reliability Division, NIST Boulder 


\section{Summary Sessions I and II}

- Database (Intel/National Labs)

- Database development (using Bob Thomas' presentation to start up)

- User groups can access available data

- Avoid rediscovering the wheel

- Commonality (Standards Bodies, Device Manufactuers)

- When it works and when it doesn't

- E.g., Within can vs. exposed

- Devices and test methods

- Standard Tests (NIST and Standard Bodies)

- Proper use

- Definition

- E.g., High/low temp for parts; leak rates

- E.g., Use $5 \mathrm{~V}$ when today lower voltages are used

- Pass/Fail criteria

- Let each group define pass/fail for medical applications

- Failure results are captured by manufacturers

- Basic models (Academia, CALCE)

- Theory and experimental data

- Interfaces

- Permeability

- Diffusion/bio-environment

- Long term hermiticity (NIST)

- Requirements

- Cans/No cans

- Corrosion (NIST)

- External and internal

- Known acceleration factors

- Proper corrosion modeling

- Environment - Need to know (NIST, FDA, Device Mfrs.)

- Chemical

- Special attention to mechanics

- Body phantoms?

- Feedback sensors 


\section{Conclusions and Summary Recommendations}

NOT NEEDED

- Medical grade components

- Medical device specific qualification standard

- Database medical device failure

\section{WHAT IS NEEDED?}

- Responsibility of each company to define use environment

- The development of non-prescriptive guidelines for device/application specific usage (Device Manufacturers)

- System or device level (group similar devices)

- Stresses applied to device

$$
\text { - Transportation, storage }
$$

- Sweat related to diet (for example)

- Thickness of skin flaps differ for varying ages

- Anatomical guideline

- Knowing animal model limitations

- Human simulator systems

- Identify stresses applied to device during assembly/manufacturing

- Standardize leak test (NIST)

- Modify methodology for measurement techniques

- Standards

- Limits

- To cover range in volumes

- To detect range in leak rates

- Gage study DSC, EDS, XPS, EDX, SIMS, CSAM, TMA

- Develop set of guidelines

- Common consensus on reporting the data

- Factor in the clinicians interfacing with their patients

\section{ACTION ITEMS}

- Schedule another meeting with a specific scope

- Liz Drexler contact for feedback 


\section{Biographies of Speakers}

Robert Baboian is a corrosion consultant with RB Corrosion Service. He retired from Texas Instruments Inc. in December, 1996, as Principal Fellow and Head of the Electrochemical and Corrosion Laboratory. His career has been dedicated toward the design and development of corrosion-resistant materials, devices, and test methods. He is the editor of 13 books, author of over 175 technical publications, and holds 15 U.S. patents. He received his B.S. degree in Chemistry from Suffolk University in 1959 and his Ph.D. in Physical Chemistry from Rensselaer Polytechnic Institute in 1964. In 1976, he was elected a TI Fellow, in 1980 a TI Senior Fellow, and in 1988 a TI Principal Fellow. The Fellow position at TI is the highest honor the company gives for scientific and technological achievement. He is also an ASTM Honorary Member, an ASTM Fellow, an SAE Fellow, a NACE Fellow, and was a Ford Foundation Postdoctoral Fellow in 1964. He received the NACE Speller Award in 1988, the ASTM LaQue Award in 1990, the Suga Foundation Award of Japan in 1991, the ASTM Cavanaugh Award in 1992, the ECS Vittorio de Nora Award in 1996, the LaQue Award of the Sea Horse Institute in 1996, the National Materials Advancement Award of the Federation of Materials Societies in 1998, the Dudley award from ASTM in 1999, and the T. J. Hull award from NACE in 2002.

Edmond Capcelea obtained his M.S. in Physics in 1987, specializing in semiconductor physics, from the University of Bucharest, Faculty of Physics. He worked for a few years as a physicist in the Safety and Probabilistic Risk Assessment department of the Cernavoda Nuclear Power Plant (Romania) and later for a brief period as the Head of Physies Department in the Biomaterials Division at a Petrochemical Institute (also in Romania). In 1992 he emigrated to Australia. After arriving in Sydney, he worked as a physicist in the Applied Physics Dept. of Sydney University, and in 1993 he was employed by Cochlear Ltd. as Reliability and Safety Engineer. In 1999 he was promoted to the Head of Reliability, Failure Analysis and Sustaining Engineering Dept at Cochlear. In mid 2003 he was promoted to the position of Head of Speech Processors Design and Development Department (Cochlear Ltd.) and this year he moved to the position of Head of Implants Design and Development Department (Cochlear Ltd.). His interests include safety and reliability of implantable devices, analogue audio design, data communication protocols, reliability of new IC packaging technologies, and nanotechnology.

Betty Collins is the Director, Division of Enforcement A, Office of Compliance, Center for Devices and Radiological Health (CDRH). She has held this position for the past three years. Prior to that, she was the Chief of the In-Vitro Diagnostics Branch for 10 years. Before coming to CDRH she worked in the Office of Regulatory Affairs for a number of years, and before that was a field investigator in the Atlanta District Office, experienced in conducting medical device, pharmaceuticals, and in-vitro diagnostic inspections. She has intensive experience in the area of regulatory case processing and enforcement activities. Her division is responsible for seven medical specialty product areas. They include Dental, Ear, Nose and Throat, Gastroenterology and Urology, General and Plastic Surgery, General Hospital, Obstetrics and Gynecology, and Ophthalmic devices. Ms. Collins holds a B.S. degree in Chemistry from South Carolina State University and worked on her M.S. in Governmental Administration at the University of Georgia. She is currently pursuing a Master of Divinity degree from Howard University in Washington, D.C. 
David Erhart received a B.S. degree in chemical engineering from the Illinois Institute of Technology, Chicago, and a Ph.D. degree in chemical engineering from the University of California, Berkeley. He is an ASQ Certified Reliability Engineer and received a professional certificate in Quality and Reliability from the University of Arizona, Tucson. David is the Director of Reliability and Product Analysis at the Medtronic Microelectronics Center, Tempe, $\mathrm{AZ}$, where he is responsible for developing and implementing strategic reliability activities during the development of implantable pulse generators (IPG) and implantable cardioverter defibrillators (ICD). Prior to joining Medtronic, he held various reliability engineering positions at ON Semiconductor and Motorola Semiconductor Products Sector.

Dominik Hammerer is an implant development engineer employed by the Austrian-based cochlear implant manufacturer MED-EL Elektromedizinische Geraete GmbH. The MED-EL implant development group is responsible for the design and development of implant electronics and their hermetic encapsulation. Additionally, the implant development group provides technical support to the implant manufacturing department with aspects related to manufacturing and testing procedures. Dr. Hammerer's activities are focused on development of hermetic implant package components, hermetic sealing technologies, such as laser welding and vacuum brazing, and definition of testing procedures and methods, applied during development and manufacturing to assure (long-term) hermeticity and mechanical stability of the devices. In addition, he is involved in root cause investigation with field-failed implants and cooperates closely with regulatory affairs in preparation of technical submissions.

Dr. Hammerer joined MED-EL Elektromedizinische Geraete GmbH, in September, 2000, after he had been working as a research fellow in the field of thermodynamic simulation at Graz University of Technology, Austria. At this same institution he received his Master's degree and $\mathrm{Ph} . \mathrm{D}$. in mechanical engineering.

Lori Henderson, of the National Institute of Standards and Technology (NIST), received her B.S. from Marygrove College in Chemistry, M.S. from University of Detroit in Macromolecular Chemistry, and later a M.S. in Organic Chemistry and Ph.D. in Polymer Science from University of Massachusetts, Lowell. Her technical expertise ranges from synthetic polymer chemistry and applied materials to molecular biology, which includes protein chemistry, microbial physiology, and enzymology.

Dr. Henderson currently works in the Polymers Division at NIST, where she is the Group Leader of the Biomaterials Group. The Biomaterials Group provides basic materials science, engineering, test methods, and standards to sectors of the health care industry for the development of new or improved materials and delivery systems, with a strong emphasis on tissue engineering and related technologies. Current project areas involve structure-property relationships in dental polymers and composites, combinatorial methods for rapid screening of biomaterials, and metrologies for tissue scaffolds.

Prior to joining NIST in January 2005, Dr. Henderson worked for BASF, Akzo Nobel Coatings, and Novozymes North America, where she was a senior scientist, global project leader, and research supervisor. Her latter appointment as a professor at North Carolina State University resulted in the start-up of a new Biomaterials-Biotechnology Center.

James K. Kane is a senior-level, scientific reviewer and team leader in the Ear, Nose, and Throat Devices Branch (ENTB) in the Office of Device Evaluation (ODE) in the Center for Devices and Radiological Health (CDRH) within the Food and Drug Administration (FDA). The 
Ear, Nose and Throat Devices Branch reviews /evaluates applications submitted by manufacturers seeking approval to market audiological, nasal and throat devices, such as hearing aids, middle-ear implants, cochlear implants, auditory brainstem implants, audiological diagnostic devices, and other ENT device products. Dr. Kane also provides scientific and regulatory support to other Offices in the Center on matters involving activities such as recalls, health hazard evaluations, and petitions for reclassification for medical devices. He represents $\mathrm{ODE}$ as the Audiology expert for the current FDA and Centers for Disease Control (CDC) investigation of the association between meningitis and cochlear implants. In addition, he is involved with standards development (ANSI, ASTM).

Prior to joining FDA in January, 2000, Dr. Kane had extensive experience in many areas of Audiology, academically and clinically, in a variety of public, private and government healthcare settings. Dr. Kane received his M.S. and Ph.D. in Audiology from the University of Pittsburgh. His post-doctoral work was conducted in the Bioacoustics Laboratory of Eye and Ear Hospital, University of Pittsburgh Medical School. His publications and presentations relate to understanding the relationships clinical diagnostic tests and auditory rehabilitation have to basic science research, and the way clinical knowledge evolves to stimulate new ideas about patient care.

Richard F. Kayser received a Sc.B. from Brown University (1973) and a Ph.D. (1976) from Rice University in physical chemistry. He joined the National Bureau of Standards (now NIST) in May 1976. Over the next 10 years, Dr. Kayser performed research in the Thermophysics Division on a wide variety of theoretical and experimental topics, ranging from phase transitions to wetting phenomena.

Dr. Kayser became Chief of the Thermophysics Division in May 1989 and Chief of the Physical and Chemical Properties Division in May 1996. In August 1999, Dr. Kayser became Director of Technology Services, which supports NIST in the provision of calibration services, Standard Reference Materials, and Standard Reference Data. In March 2004, Dr. Kayser served as Acting Deputy Director and Chief Operations Officer, NIST. In July 2005, Dr. Kayser was named Acting Director of the Materials Science and Engineering Laboratory (MSEL). MSEL provides technical leadership for the nation's materials measurement and standards infrastructure, using its expertise to anticipate and respond to measurement-related industry needs in many technology sectors, including microelectronics, automotive, and health care.

Dr. Kayser has participated in numerous outside activities over the years. He currently serves on the Board of Directors of ASTM International.

Joaquin V. Martinez de Pinillos is a senior scientist at the National Institute of Standards and Technology (NIST). He joined this institution in 1999 after 24 years at Air Products and Chemicals, Inc., in Allentown, PA. He started at Air Products in 1975 as a Research Chemist and continued with positions of higher responsibility and retired in 1999 as the Senior Research Associate and Manager, Analytical Technology of the Electronics Division. Prior to that, he had worked at American Cyanamid Co., and Cyclo Chemicals Corp. He received a Ph.D. in Chemical Physics from the University of Florida in 1974, and M.A. in Physical Chemistry from Bowling Green State University in 1968, and a B.S. in Chemistry from the University of Miami in 1966. He has published several papers and is the author of several patents.

Keith McLain heads the Quality Assurance group at Advanced Bionics; a Boston Scientific Company. His group provides reliability and quality engineering services that 
support the development and manufacture of neuro stimulation devices that include cochlear implants and pain management systems. Mr. McLain has over 20 years applying reliability methods to complex systems. Previously, he managed reliability engineering groups at Ortho Clinical Diagnostics and Bayer Diagnostics. He has developed comprehensive reliability programs for several in vitro diagnostic products. His areas of expertise include Reliability Growth Modeling, Reliability Growth Testing, Integrated Fault Tree/FMECA, Reliability Program Planning, and Remote Diagnostics. Prior to working in the medical device industry, Mr. McLain was a member of the technical staff at The Analytical Science Corporation (TASC) where he provided reliability consulting services to the automotive, aerospace, and semiconductor manufacturing industries. He holds B.S. and M.S. degrees from Case Western Reserve University.

His publications include:

1. Robert Gates, Greg Gibson, Keith McLain: "Reliability Growth Prediction," 1986, Reliability Analysis Center (RAC)

2. Jan S. Krouwer and Keith McLain: Predicting and Improving Product Quality, Critical Care Business Leadership Forum, Coalition for Critical Care, September, 1998 Andover, MA

3. Warren and McLain: "Automated analysis of life data of missiles in storage and flight," 1990, RAMS Proceedings

4. "FRACAS: The Most Effective Reliability Improvement Tool?," 1993, Forty-Ninth Annual Quality Control Conference, Rochester ASQC

5. "Improving the Reliability of Diagnostic Systems," Medical Device and Diagnostic Industry, January 1994

6. "Experiences using a Hybrid Fault Tree and FMECA Tool in the Medical Diagnostics Industry," 2001 IEEE Boston Spring Reliability Symposium

Ali Mosleh is professor and director of the Reliability Engineering Program and director of the Center for Risk and Reliability at the University of Maryland. He conducts research on methods for reliability of complex systems and probabilistic risk analysis (PRA), and has made many contributions in diverse fields of theory and application. These include Bayesian methods for inference with uncertain evidence; analysis of data and expert judgment; treatment of model uncertainty; risk and reliability of hybrid systems of hardware, human and software; methods and tools for dynamic PRA; cognitive models for human reliability analysis; and models of the influence of organizational factors on system reliability and safety. He is the developer of the Accident Precursor Analysis methodology and many of the methods currently used for the treatment of common causes of failures in highly reliable systems. On these topics he holds several patents, and has edited, authored or co-authored more than 250 publications including books, guidebooks and papers in technical journals and for conferences.

Dr. Mosleh has led numerous projects on reliability, risk, safety, and security assessments for the aerospace, nuclear, chemical, and information systems and telecommunication industries. He also led the design and development of more than 10 major risk and software packages for reliability analysis currently in use by various government agencies and the private sector.

Dr. Mosleh was appointed by President George W. Bush in 2004 to the U.S. Nuclear Waste Technical Review Board for a four- year term. He is a Fellow of the Society for Risk Analysis (SRA), Chair of the Engineering Division of SRA, and Engineering Editor of the SRA Journal. He is the recipient of several scientific achievement awards, and a consultant and technical advisor to national and international organizations on reliability analysis and risk assessment. He 
has chaired or organized numerous international technical conferences on risk and reliability. Dr. Mosleh received his Ph.D. in Engineering from the University of California, Los Angeles in 1981.

Bob Munroe has 43 years of experience in electronics packaging design and manufacturing from first level to box level including structural and cooling design, second level packaging, and device interconnections of all kinds. The first 16 years involved military and aerospace packaging (man-rate). Bob was employed by IBM from 1961 to 1991 and by Motorola from 1991 to 2000. He has done considerable work involving appropriate qualification and engineering evaluation tests during this period. He has several patents, technical papers, and corporate awards for performance.

Celeste Null currently leads Biomedical Engineering in the Digital Health Group of Intel Corporation. Celeste has held engineering management positions in all facets of semiconductor manufacturing, including product, process, and technology development, as well as design, qualification, and customer engagements. Her pathfinding work has included development of quality systems, chaos modeling in risk management, automated product qualification systems, operation/planning development, and software quality engineering. She was a key developer of Intel's initial biotechnology strategies.

She has chaired the national liaison Solid State Technology Division of JEDEC, where she led international specification developments in Residual Gas Analysis, Statistical Process Control, Process Characterization, and Tape Automated Bonded military packaging. She is a member of JEDEC JC-13 (reliability) and JC-14 (Quality Systems), the Electronics Industry Alliance Quality/Reliability Engineering Working Group, and serves on the U.S. N.S.F.supported Management of Accelerated Technology Innovation. At Intel, Celeste is a member of the Nanotechnology Safety Board and received the 2002 Leadership Breakthrough Award for quality management systems. She is a Senior Member of the American Society of Quality, a Certified Quality Auditor, an ISO 9001:2000 RAB national certified auditor, and a certified Baldrige Award examiner for California and Arizona. At Arizona State University, she has served on the Advisory Board for the Biodesign Institute, the Bioengineering Advisory Committee, and was founding member of Alpha Eta Mu Beta, a bioengineering honor society. She currently is on the editorial board for the Journal of Biomedical Microdevices as well as the Scientific Advisory Board for the World Nanotechnology Conference.

Prior to coming to Intel in 1995, Celeste was with Medtronic Corporation, Fairchild Semiconductor Corporation, and Texas Instruments.

Celeste has a B.S. in Microbiology and Chemistry from Texas Tech University, a Master's degree in Bioengineering from Arizona State University, and is currently completing her doctoral work in Bioengineering at ASU in bioelectricity. She and her husband, Randy, have two boys, and are community leaders with the Ahwatukee YMCA.

Michael Pecht has a B.S. in Acoustics, an M.S. in Electrical Engineering and an M.S. and Ph.D. in Engineering Mechanics from the University of Wisconsin at Madison. He is a Professional Engineer, an IEEE Fellow and an ASME Fellow. He has received the 3M Research Award, the IEEE Undergraduate Teaching Award, and the IMAPS William D. Ashman Memorial Achievement Award for his contributions. He has written 18 books on electronic products development, use, and supply chain management. He has also edited a series of books on the Asian electronics industry including a recent book titled "The Chinese Electronics 
Industry - 2004 edition." He served as chief editor of the IEEE Transactions on Reliability for eight years and on the advisory board of IEEE Spectrum. He is the founder and the Director of the CALCE Electronic Products and Systems Center at the University of Maryland and a Chair Professor. He is chief editor for Microelectronics Reliability and an associate editor for the IEEE Transactions on Components and Packaging Technology. He has consulted for over 50 major international electronics companies, providing expertise in strategic planning, design, test, IP, and risk assessment of electronic products and systems.

Stan Purwin is Manager of Supplier Quality Assurance at the Johns Hopkins University/Applied Physics Lab (APL) Space Department where he is a member of their Principal Professional Staff. For the last decade he was the Group Supervisor of Safety, Quality, and Reliability for the Space Department. He supervised all quality, reliability, safety, material acquisition (principally electronics), and contamination control on all spacecraft. Prior to joining APL he was the Director of Manufacturing at a former division of a Fortune 10 Company. He has held allied positions at other Fortune 10 companies. He holds a B.Eng in Electronics, a M.S.ME, and an MBA. He was formerly a registered Professional Engineer and an American Society for Quality (ASQ) Quality Engineer. He is currently an ASQ certified Quality Manager and ASQ certified Software Quality Engineer.

William Regnault is the Senior Materials Scientist for the Division of Chemistry and Materials Science (DCMS) within the Office of Science and Engineering Laboratories (OSEL) of the Center for Devices and Radiological Health (CDRH). After graduating from The Pennsylvania State University, Dr. Regnault worked for a photovoltaic firm developing low-cost silicon-based alternative solar cells. Dr. Regnault joined the Government and CDRH as a materials scientist in 1985, where he has worked on numerous projects dealing with the effects of fabrication processes and in-use service conditions on the long-term stability and reliability of biomaterials and medical devices.

Ken Rodbell is a Research Staff Member and Manager of the Thin Film Metallurgy and SER Research Department at the IBM Thomas J. Watson Research Center in Yorktown Heights, NY. He joined IBM Research in 1989 after spending three years at the IBM Semiconductor Development Laboratory in East Fishkill, NY. Dr. Rodbell received his B.S. (1982), M.S. (1983) and Ph.D. (1986) in Materials Science and Engineering from Rensselaer Polytechnic Institute. He also worked at Fairchild Camera and Instrument Company, South Portland, ME (1982) and Carpenter Technology, Bridgeport, CT (1981). Dr. Rodbell's research interests have focused on Si-based electronic materials; specifically thin film metallurgy and crystallographic texture, electromigration, chemical mechanical polishing, 1/f noise in metallic films, positron annihilation spectroscopy, radiation induced soft errors, and low-k dielectric materials. He has co-authored more than 100 publications and more than 40 issued U.S. patents (named Master Inventor at IBM Research in 2003) and has given numerous invited talks. He is a reviewer for JAP, APL and the J. Vac. Sci. and Tech. He has served on program committees for the IEEE, ICOTOM, NSREC, MRS and the International Workshop on Stress-Induced Phenomena in Metallization and is a member of the Editorial Advisory Board for Materials Science in Semiconductor Processing. He is also a member of the external advisory committee for the Materials Science and Engineering department at Johns Hopkins University. 
Michael Schen is Group Leader of the NIST Advanced Technology Program's Electronics and Photonics Group of the Information Technology and Electronics Office. He joined ATP in 1997. ATP, a cost-sharing program, helps American industry invest in longer-term, high risk research with payoffs far beyond private profit. ATP investments accelerate the development of early-stage, innovative technologies that help industry raise its competitive potential and provide Americans with a higher standard of living.

Since 1991, approximately $30 \%$ of the 768 projects funded by ATP involve direct developments in biotechnology and/or healthcare related technologies. This translates to approximately \$620 million that ATP has awarded to 224 biotechnology and/or healthcare projects, with an industry's cost share of more than $\$ 516$ million, thus stimulating more than $\$ 1.13$ billion of biotechnology and/or healthcare R\&D.

Prior to joining ATP, Michael was a Program Analyst for the NIST Director's Office; Program Manager within the NIST Laboratories; a NIST staff scientist; and a research chemist at the Eastman Kodak Co.

Michael completed a Fulbright and French Government co-sponsored post-doctoral appointment at the Université de Montpellier, CNRS Laboratories, in Montpellier, France; received his Ph.D. in Polymer Science and Engineering from the University of Massachusetts in Amherst; gained his Bachelor's degree in chemistry from the Rochester Institute of Technology, Rochester, NY; and received his Associates in Applied Sciences from the State University of New York at Alfred.

John S. Suehle received his B.S., M.S., and Ph.D. degrees in electrical engineering from the University of Maryland, College Park, in 1980, 1982, and 1988 respectively. In 1981 he received a Graduate Research Fellowship with the National Institute of Standards and Technology (NIST), Gaithersburg, MD. Since 1982 he has been working in the Semiconductor Electronics Division at NIST, where he is leader of the Advanced MOS Device Reliability and Characterization Project. His research activities include failure and wear-out mechanisms of semiconductor devices, radiation effects on microelectronic devices, micro-electro-mechanicalsystems (MEMS), and molecular electronic devices. Dr. Suehle is currently serving on the management committees of the IEEE International Reliability Physics Symposium and the IEEE Integrated Reliability Workshop. Both conferences deal exclusively with reliability physics of microelectronic devices. He also serves as the chairman of the Oxide Integrity Working Group of the EIA/JEDEC JC 14.2 Standards Committee responsible for developing national standard test procedures for wafer-level reliability. He is a Senior member of IEEE.

Robert Thomas has a Ph.D. in solid state science from Syracuse University. He was an engineer and manager at Rome Air Development Center for 32 years, retiring from the Air Force in 1992. A major portion of his career focused on developing techniques for moisture measurement of integrated circuit packages. A portion on his accomplishments includes: managing an AF contract with John Pernicka to commercialize the first rapid cycle mass spectrometer residual gas analysis system, coauthoring with Connie Zierdt of Bell Labs, MILSTD 883 Test Method 1018 for control of moisture in integrated circuit packages, performing gas analysis on packages from the Apollo and Viking Mars Lander, hosting NBS/NIST workshops on Pacemakers and integrated circuit moisture measurement, conducting round robin inter-laboratory correlation tests, participating in the development of the three volume calibration valve for RGA analysis, as well as authoring many papers on moisture and contamination control. Dr. Thomas is currently a principal partner in Arthur Jonath Associates, an expert 
network assisting medical and aerospace companies in quality and reliability analysis. Dr. Thomas is an RADC Fellow and a Life Fellow of the IEEE.

Jan Welch is a Consumer Safety Officer in the U.S. Food and Drug Administration's Center for Devices and Radiological Health, Office of Compliance, Division of Enforcement A, in Rockville, Maryland. She has been in this position for 11 years. Mrs. Welch is a medical device Quality System Expert with additional expertise in the areas of process validation, design control, and in vitro diagnostic devices. Mrs. Welch serves as one of CDRH's Quality System experts in medical device legal actions involving complex and precedent-setting regulatory actions involving medical devices and specifically in vitro diagnostic devices. Mrs. Welch is a member of several FDA Course Advisory Groups where she develops, plans, and presents training courses for FDA staff in areas pertaining to devices.

Mrs. Welch is a representative to ISO TC 210 [Quality Management and Corresponding General Aspects for Medical Devices], Working Group 1 [Application of Quality Systems to Medical Devices]. Mrs. Welch is also a member of the Global Harmonization Task Force, Study Group 4, Regulatory Auditing.

Prior to her position with CDRH, Mrs. Welch worked for over four years in FDA's Center for Biologics Evaluation and Review, Office of Compliance, Division of Case Management. Prior to her employment with the FDA, Mrs. Welch worked for the American Red Cross in Washington, DC, the National Institutes of Health in Bethesda, MD, and Vanderbilt University Medical Center in Nashville, TN.

Mrs. Welch graduated with a B.A. in Biology from Wake Forest University, completed a one-year certificate program in Medical Technology at Vanderbilt University, and earned a Masters degree in Health Sciences in Immunohematology from the Medical University of South Carolina. She is an ASCP registered Medical Technologist and Specialist in Blood Banking. 


\section{List of Attendees and Participants}

Kay Adair

Advanced Bionics Corp.

12740 San Fernando Rd.

Sylmar, CA 91342 USA

Phone: (661)362-1669 ext. 1669

Fax: (661)362-1511

Email: Kay.Adair@advancedbionics.com

Lawrence Arne

Proteus Biomedical

750 Chesapeake Dr.

Redwood City, CA 94063 USA

Phone: (650)568-0580 ext. 122

Email: larne@proteusbiomed.com

Merry Bain

Falcon Advisors

P.O. Box 2672

West Lafayette, IN 47996 USA

Phone: (765)564-1056

Fax: (765)564-2187

Email:mleebain@insightbb.com

Michael Bazaral

FDA

2094 Gaither Rd.

HFZ 340

Rockville, MD 20850 USA

Email:mgb@cdrh.fda.gov

Susan Bowley

FDA/CDRH/ODE/DCD

9200 Corporate Blvd.

HFZ-450

Rockville, MD 20850 USA

Email:sub@cdrh.fda.gov
Patti Arndt

Cochlear Americas

400 Inverness Pkwy.

Ste. 400

Englewood, CO 80112 USA

Phone: (303)524-7162

Fax: (303)524-6764

Email: parndt@cochlear.com

Robert Baboian

RB Corrosion Service

84 Ruff Stone Rd.

Greenville, RI 02828 USA

Phone: (401)949-5398

Fax: (401)949-1661

Email: rbaboian@aol.com

Karen Baker

FDA/CDRH/ODE/DOED

9200 Corporate Blvd.

HFZ-460

Rockville, MD 20850 USA

Email:khb@cdrh.fda.gov

Peter Borgesen

Universal Instruments Corp.

P.O. Box 825

Binghamton, NY 13902 USA

Phone: (607)779-7343

Email: borgesen@uic.com

Nancy Brehm

Cochlear Americas

400 Inverness Pkwy.

Ste. 400

Englewood, CO 80112 USA

Phone: (303)524-7122

Fax: (303)524-6764

Email: nbrehm@cochlear.com 
Charles Byers

Alfred Mann Foundation

25134 Rye Canyon Loop

P.O. Box 905

Santa Clarita, CA 91380-9005 USA

Phone: (661)702-6734

Fax: (661)702-6711

Email: chuckb@aemf.org

Dulciana Chan

FDA/CDRH

12725 Twinbrook Pkwy.

Rockville, MD 20852 USA

Email: dulciana.chan@fda.hhs.gov

Ethan Cohen

OSEL/CDRH/FDA

HFZ130

12725 Twinbrook Blvd.

Rockville, MD 20853 USA

Phone: (301)827-4953

Fax: (301)827-4947

Email: edc@cdrh.fda.gov

\section{Betty Collins}

FDA

2094 Gaither Rd.

Rockville, MD 20850 USA

Phone: (240)276-0115

Fax: (240)276-0114

Email: byc@cdrh.fda.gov

John Daley

Cordis Corp.

7 Powderhom Dr.

Warren, NJ 07059 USA

Phone: (909)412-3258

Fax: (908)412-3737

Email: maimovi1@crdus.jnj.com
Edmond Capcelea

Cochlear, Ltd.

14 Mars Rd.

Lane Cove, 2066 NSW AUSTRALIA

Phone: 61294286573

Fax: 61294286264

Email: ecapcelea@cochlear.com.au

Keith Checca

Texcel LLC

55 Deer Park Dr.

East Longmeadow, MA 01028 USA

Phone: (413)525-5700 ext. 1026

Email:kchecca@texcelaser.com

Dean Cole

U.S. Dept. of Energy

1000 Independence Ave., SW

Washington, DC 20585-1290 USA

Phone: (301)903-3268 ext. 0

Email: dean.cole@science.doe.gov

Teri Cygnarowicz

FDA/CDRH/ODE/DOED

9200 Corporate Blvd.

HFZ-460

Rockville, MD 20850 USA

Email: tyc@cdrh.fda.gov

Bob De Luca

9200 Corporate Blvd.

HFZ-410

Rockville, MD 20850 USA

Email: rjd@cdrh.fda.gov 
Elizabeth Drexler

NIST

325 Broadway

Div 853

Boulder, CO 80305 USA

Phone: (303)497-5350

Fax: (303)497-5030

Email: drexler@boulder.nist.gov

Diane Dwyer

FDA

1350 Piccard Dr.

HFZ 520

Rockville, MD 20850 USA

Phone: (301)594-2385

Fax: (301)594-1967

Email: ded@cdrh.fda.gov

David Erhart

Medtronic Microelectronics Ctr.

2343 W. Medtronic Way

Tempe, AZ 85284 USA

Email: david.erhart@medtronic.com

Shaw Feng

NIST

100 Bureau Dr.

Mail Stop 8263

Gaithersburg, MD 20899-8263 USA

Phone: (301)975-5777

Fax: (301)975-4482

Email: shaw.feng@nist.gov

Valerie Flournoy

FDA

2094 Gaither Rd.

Rockville, MD 20850 USA

Phone: (240)276-0115

Fax: (240)276-0114

Email: vaf@cdrh.fda.gov
Tithi Dutta Roy

NIST

100 Bureau Dr.

Mail Stop 8543

Gaithersburg, MD 20899-8543 USA

Phone: (301)975-6747

Email: tithi.duttaroy@nist.gov

Lynn Elliott

Guidant Corp.

4100 Hamline Ave., N

St. Paul, MN 55112 USA

Email: lynn.elliott@guidant.com

Boozarjomehr Faraji

Second Sight Medical Products, Inc. 12744 San Fernando Rd.

Bldg. 3

Sylmar, CA 91342 USA

Email: bfaraji@2-sight.com

Robert Fischer

FDA/CDRH/OSB/DPS/PEB/II

1350 Piccard Dr.

HFZ520

Rockville, MD 20850 USA

Phone: (301)594-3585

Fax: (301)594-2965

Email: raf@cdrh.fda.gov

Beverly Gallauresi

FDA

1350 Piccard Dr.

HFZ520

Rockville, MD 20850 USA

Phone: (301)594-2101

Fax: (301)594-1967

Email: bxg@cdrh.fda.gov 
Xiao-Yan Gong

Nitinol Devices \& Components

47533 Westinghouse Dr.

Fremont, CA 94539 USA

Phone: (510)498-1819

Fax: (510)623-6808

Email:xgong@ndcus.jnj.com

Jove Graham

FDA

12725 Twinbrook Pkwy.

HFZ170

Rockville, MD 20852 USA

Phone: (301)827-4882

Fax: (301)827-4853

Email: jhg@cdrh.fda.gov

Brian Greig

St. Jude Medical

8300 E. Pacesetter Way

Scottsdale, AZ 85255 USA

Email: bgreig@sjm.com

Lori Henderson

NIST

100 Bureau Dr.

Mail Stop 8543

Gaithersburg, MD 20899-8543 USA

Phone: (301)975-4348

Email: lori.henderson@nist.gov

Vivianne Holt

FDA/CDRH/ODE/DCD

9200 Corporate Blvd.

HFZ460

Rockville, MD 20850 USA

Phone: (301)443-8243 ext. 170

Email:vzh@cdrh.fda.gov

Marcus Ignacio

Cochlear, Ltd.

14 Mars Rd.

Lane Cove, 2066 NSW AUSTRALIA

Phone: 61294255216

Fax: 61294286264

Email:mignacio@cochlear.com.au
Hernando Gonzalez

Second Sight Medical Products, Inc.

12744 San Fernando Rd.

Bldg. 3

Sylmar, CA 91342 USA

Email: tfisher@2-sight.com

Robert Greenberg

Second Sight Medical Products, Inc. 12744 San Fernando Rd.

Bldg. 3

Sylmar, CA 91342 USA

Email: tfisher@2-sight.com

Dominik Hammerer

MED EL

Furstenweg 77, A 6020

Innsbruck, 43 AUSTRIA

Phone: 43512288889462

Email: dominik.hammerer@medel.com

Greg Hertzig

Sandell Asset Management

40 W. 57 th St.

26th Floor

New York, NY 10019 USA

Phone: (212)603-5700

Email: ghertzig@sandellmgmt.com

Tonya Icenogle

FDA

9200 Corporate Blvd.

HFZ150

Rockville, MD 20850 USA

Phone: (301)827-4876

Marc Jensen

Proteus Biomedical

750 Chesapeake Dr.

Redwood City, CA 94063 USA

Phone: (650)568-0580 ext. 107

Email: mjensen@proteus.bz 
Guangqiang Jiang

Alfred Mann Foundation

25134 Rye Canyon Loop

Santa Clarita, CA 91355 USA

Phone: (661)702-6700 ext. 6766

Fax: (661)702-6711

Email: jiang@aemf.org

\section{Soma Kalb}

U.S. FDA

1350 Piccard Dr.

HFZ520

Rockville, MD 20850 USA

Phone: (301)594-2581

Fax: (301)594-1967

Email: sxk@cdrh.fda.gov

David Kaplan

U.S. FDA

12725 Twinbrook Pkwy.

HFZ170

Rockville, MD 20852 USA

Phone: (301)827-4754

Fax: (301)827-4853

Email: david.kaplan@fda.hhs.gov

James Little

Second Sight Medical Products, Inc.

12744 San Fernando Rd.

Bldg. 3

Sylmar, CA 91342 USA

Email:jiml@2-sight.com

Beverly Lorell

Guidant Corp.

111 Monument Cir.

Ste. 2900

Indianapolis, IN 46204 USA

Phone: (317)971-2204

Fax: (317)971-2208

Email: beverly.lorell@guidant.com
Lee Johnson

SFA, Inc. for Naval Res. Lab.

Naval Res. Lab.

4555 Overlook Ave.

Washington, DC 20375 USA

Phone: (202)404-3752

Email: ljohnson@nrl.navy.mil

James Kane

U.S. FDA

9200 Corporate Blvd.

Rockville, MD 20850 USA

Phone: (301)597-2080

Fax: (301)480-4201

Email: james.kane@fda.hhs.gov

Peter Lampacher

VIBRANT MED-EL AMBH

Fuerstenweg $77 \mathrm{a}$

Innsbruck, 6020 AUSTRIA

Phone: 43512288889256

Fax: 43512288889299

Email: peter.lampacher@medel.com

Chih-hsin Liu

U.S. FDA

1350 Piccard Dr.

HFZ520

Rockville, MD 20850 USA

Phone: (301)594-3948

Fax: (301)594-1967

Email:chl@cdrh.fda.gov

Qijin Lu

U.S. FDA

12725 Twinbrook Pkwy.

HFZ170

Rockville, MD 20852 USA

Phone: (301)827-5626

Fax: (301)827-5604

Email: qx14@cdrh.fda.gov 
Marian Maghribi

NDC

47533 Westinghouse Dr.

Fremont, CA 94539 USA

Phone: (510)498-1809

Email:mmaghribi@ndcus.jnj.com

Suzanne Malli

U.S. FDA

1350 Piccard Dr.

HFZ520

Rockville, MD 20850 USA

Phone: (301)594-3660

Fax: (301)594-1967

Email:swm@cdrh.fda.gov

Eric Mann

FDA/CDRH/ODE/DOED

9200 Corporate Blvd.

HFZ460

Rockville, MD 20850 USA

Email: exm@cdrh.fda.gov

Steve Maschino

Cyberonics, Inc.

100 Cyberonics Blvd.

Ste. 600

Houston, TX 77058 USA

Phone: (281)228-7232

Fax: (281)291-9332

Email: sem@cyberonics.com

Stephen Meeks

St. Jude Medical-CRMD

8300 E. Pacesetter Way

Scottsdale, AZ 85255 USA

Phone: (480)502-6360 ext. 6428

Fax: (480)502-6417

Email:smeeks@sjm.com
Subhas Malghan

U.S. FDA

12725 Twinbrook Pkwy.

HFZ100

Rockville, MD 20852 USA

Phone: (301)827-4777

Fax: (301)827-4787

Email: subhas.malghan@fda.hhs.gov

Vasant Malshet

FDA/CDRH/ODE/DOED

9200 Corporate Blvd.

HFZ460

Rockville, MD 20850 USA

Email:wgm@cdrh.fda.gov

Jack Martinez

NIST

100 Bureau Dr.

Mail Stop 8101

Gaithersburg, MD 20899-8101 USA

Phone: (301)975-8125

Fax: (301)975-6513

Email: jack.martinez@nist.gov

Keith McLain

Advanced Bionics

25129 Rye Canyon Loop

Valencia, CA 91355 USA

Phone: (661)352-1833

Email: kmclain@advancedbionics.com

Audrey Morrison

CDRH

13705 Modrad Way

Silver Spring, MD 20904 USA

Phone: (301)827-7534

Email: axm@cdrh.fda.gov 
Ali Mosleh

Univ. of Maryland

2100 A Marie Mount

College Park, MD 20742 USA

Phone: (301)405-5215

Fax: (301)314-9601

Srinivas Nandkumar

9200 Corporate Blvd.

HFZ460

Rockville, MD 20850 USA

Email:szn@cdrh.fda.gov

Michael Pecht

CALCE EPSC - Univ. of MD

1103 Eng. Lab Bldg.

College Park, MD 20742 USA

Email:pecht@calce.umd.edu

Dave Peterson

Advanced Bionics

25129 Rye Canyon Loop

Valencia, CA 91355 USA

Phone: (661)362-1768

Fax: (661)362-1508

Email: dpeterson@advancedbionics.com

Stan Purwin

Johns Hopkins Univ.

Applied Physics Lab.

11100 Johns Hopkins Rd.

Laurel, MD 20723 USA

Phone: (240)228-6279

Email: stan.purwin@jhuapl.edu

Bill Regnault

U.S. FDA

9200 Corporate Blvd.

HFZ150

Rockville, MD 20850 USA

Phone: (301)827-4748

Fax: (301)827-4853

Email:wfr@cdrh.fda.gov
Robert Munroe

Electronic Packaging Consultant

16 Avalon Dr.

Trophy Club, TX 76262 USA

Phone: (682)831-0993

Email: munroe.bob@sbcglobal.net

Celeste Null

Intel Corp.

5000 W. Chandler Blvd.

CH7318

Chandler, AZ 85226 USA

Phone: (480)554-0248

Fax: (480)554-7490

Email: celeste.null@intel.com

John Pernicka

Pernicka Corp.

112 Racquette

Fort Collins, CO 80524 USA

Email: rga@pernicka.com

Eric Peterson

Guidant Corp.

4100 Hamline Ave., N

MS C260

St. Paul, MN 55112 USA

Phone: (651)582-2965

Fax: (651)582-2945

Email: eric.peterson@guidant.com

Richard Raisner

Texcel LLC

55 Deer Park Dr.

E. Longmeadow, MA 01028 USA

Phone: (413)525-5700 ext. 1011

Fax: (413)525-6644

Email: rraisner@texcelaser.com

Charles Reid

Guidant

4100 Hamline Ave., N

Mail Stop E105

St. Paul, MN 55112 USA

Phone: (651)582-4110

Fax: (651)582-7599

Email: chuck.reid@guidant.com 
Ron Reimann

Guidant CRM

4100 Hamline Ave., N

St. Paul, MN 55112 USA

Phone: (651)582-4629

Fax: (651)582-2830

Email: ron.reimann@guidant.com

Anne-Marie Ripley

Second Sight Medical Products, Inc.

12744 San Fernando Rd.

Bldg. 3

Sylmar, CA 91342 USA

Email: tfisher@2-sight.com

Arup Roy

Second Sight Medical Products, Inc.

12744 San Fernando Rd.

Bldg. 3

Sylmar, CA 91342 USA

Email: arupr@2-sight.com

Joseph Schulman

Alfred Mann Foundation

P.O. Box 905

Santa Clarita, CA 91380 USA

Phone: (661)702-6700 ext. 6811

Fax: (661)702-6705

Email: joes@aemf.org

Louis Skarda

Guidant

4100 Hamline Ave., N

St. Paul, MN 55112 USA

Phone: (651)582-2187

Email: louis.skarda@guidant.com

Gail Strieter

U.S. FDA, CDRH/OSEL

12720 Twinbrook Pkwy.

HFZ84

Rockville, MD 20850 USA

Phone: (301)827-0027

Fax: (301)827-9097

Email: gail.strieter@fda.hhs.gov
Karen Riley

Clinica: World Medical Tech. News

4004 Jefferson St.

Hyattsville, MD 20781 USA

Phone: (301)927-1485

Fax: (301)927-1486

Email: kjriley@ccconline.net

Kenneth Rodbell

IBM Watson Res.

1101 Kitchawan Rd., Rt. 134

Yorktown Heights, NY 10598 USA

Phone: (914)945-1012

Fax: (919)945-2141

Email: rodbell@us.ibm.com

Michael Schen

NIST

100 Bureau Dr.

Mail Stop 4720

Gaithersburg, MD 20899 USA

Phone: (301)975-6741

Email: michael.schen@nist.gov

Andreas Schweinzer

BIOTRONIK GmbH \& Co. KG

Woermannkehre 1

Berlin, 12359 GERMANY

Phone: 493068905 ext. 4316

Email: andreas.schweinzer@biotronik.de

Matthew Stonehouse

Guidant CRM

4100 Hamline Ave., N

Arden Hills, MN 55112 USA

Phone: (651)582-6572

Fax: (651)582-2830

Email: matthew.stonehouse@guidant.com

Ravi Subrahmanyan

Micro Sys. Eng., Inc.

6024 S.W. Jean Rd.

Lake Oswego, OR 97035 USA

Phone: (503)697-5281

Email: ravi.subrahmanyan@biotronik.com 
John Suehle

NIST

100 Bureau Dr.

Mail Stop 8123

Gaithersburg, MD 20899-8123 USA

Phone: (301)975-2247

Fax: (301)975-5668

Email: john.suehle@nist.gov

Alford Taylor

U.S. FDA, CDRH

Bldg. 1 HFZ-160

12720 Twinbrook Pkwy.

Rockville, MD 20851-1720 USA

Phone: (301)443-2536 ext. 147

Fax: (301)443-9101

Email: Alford.Taylor@fda.hhs.gov

Robert Thomas

Tech. Experts Network

104 Cedar St.

Rome, NY 13440 USA

Phone: (315)336-0286

Fax: (315)336-0286

Email: bobtrome@aol.com

Jan Welch

U.S. FDA

2094 Gaither Rd.

Rockville, MD 20850 USA

Phone: (240)276-0354

Fax: (240)276-0114

Email: jan.welch@fda.hhs.gov

Joyce Whang

U.S. FDA

12725 Twinbrook Pkwy.

Rm. 235

Rockville, MD 20852 USA

Fax: (301)827-0421

Email:.jmw@cdrh.fda.gov
Ronald Swann

U.S. FDA

2094 Gaither Rd.

Rockville, MD 20850 USA

Phone: (240)276-0115

Fax: (240)276-0114

Email: rzs@cdrh.fda.gov

John Tesk

NIST

100 Bureau Dr.

Mail Stop 8545

Gaithersburg, MD 20899-8545 USA

Phone: (301)975-6799

Email: john.tesk@nist.gov

Jeffrey Toy

U.S. FDA/CDRH/ODE/DOED

9200 Corporate Blvd.

HFZ460

Rockville, MD 20850 USA

Email: jyt@cdrh.fda.gov

Stuart Wenzel

NDC

47533 Westinghouse Dr.

Fremont, CA 94539 USA

Phone: (510)413-1133

Email: swenzel@ndcus.jnj.com

Eileen Woo

U.S. FDA

1350 Piccard Dr.

HFZ520

Rockville, MD 20850 USA

Phone: (301)594-2446

Fax: (301)594-1967

Email: ekw@cdrh.fda.gov 


\section{Comments from the Organizing Committee}

Personal impressions of John A. Tesk about the workshop on active implantable medical devices (AIMDs):

1. The workshop was attended by the AIMD industry mainly because it was an FDA workshop and it seems that whenever the FDA puts on a workshop, industry feels compelled to attend in order to keep up with what might be new developments that affect them.

2. The Industry failed to grasp what was clearly stated in the purpose of the workshop, namely; "The objective is to help identify the technical and measurement issues that are involved in the use of both national and international standards for the assessment of the reliability of active implantable medical devices. It is the intention of this workshop to help define the areas for future work that will facilitate the rapid deployment of advanced implant technologies." In general, industry came expecting measurements to be given to them rather than their partaking in the identification of generic needs for standards and measurements that should be developed soon for the future good of the industry, customers, and patients.

3. There was a reluctance on the part of the industry to say much in the presence of the FDA, which had a great presence (in numbers) at the workshop, in short, the FDA was feared more than being seen as a potential partner in arriving at good standards that could be of benefit to all.

4. The workshop had a beneficial effect in bringing together the major developers of the different kinds of AIMDs and elucidating problems that need to be overcome for greater cooperation in the development of consensus standards, such as those that already exist between the FDA and The ASTM F04 Standards Committees and through the Orthopaedic FDA Forum, a regular meeting of the FDA and orthopaedic surgical device manufacturers. Something like the latter should be attempted between the FDA and the AIMD industry. Perhaps the AIMD Industry could be invited to one of the Orthopaedic Device Forum meetings to observe how it functions and to hear from the Orthopedic Industry about its effectiveness. I recommend this or, at least, asking the Orthopaedic Forum participants to consider setting aside a couple of hours to meet with the AIMD industry just prior to or after an Orthopaedic Device Forum meeting.

5. Major issues in the measurement methods for leak detection and validation of those methods were acknowledged by all. NIST was chided for not having produced the needed measurement methods and "reference materials" for calibration of low level helium leak tests.

6. Leak test models for various kinds of leaks through tortuous paths through different kinds of materials and combinations of materials, including seals between materials comprising a "can" are needed.

7. This observer sees the possibility of extending the kind of modeling used for fluid transport through scaffolds used for tissue engineering and models for permeation of resins for fiber composites to serve as starting points for modeling of leaks. Many such geometrical models already exist in the MSEL that would obviate the need to start from the beginning all over again; two-three years of effort could be avoided. Nearly immediate extension to much smaller scales could begin with material/fluid property, then interactions based on size could begin to be added and effects validated. 
8. The time is now ripe for holding follow-up workshops that will focus on individual or related issues; it may be necessary for NIST to lead some without the FDA directly co-hosting and others may require the FDA via interactions with Standards Development Organizations. 
I believe that there are two parallel AIMD needs to be fulfilled. The October 2005 workshop was very successful in getting the FDA scientists and engineers talking with one another, members of the FDA Device Evaluation Group (those who qualify new devices and set the necessary test standards and requirements) and the Compliance Group (those who assure that the qualifying tests and standards are properly applied). Individuals within these groups specialize in particular devices. But in the past there has been little interaction and discussion within a group and between groups about holding all AIMDs to the same standards. The FDA people learned a lot from our speakers, but further education in the form of workshops could be valuable.

The second group, of course, is the AIMD manufacturers. As I see it, they need to design, qualify, and manufacture highly reliable devices, so that they get product to market in a timely fashion, with negligible numbers of failures in service. It would seem that it would be to their benefit to cooperate on finding solutions to problems that are universal. I think that they are starting to see this as well, based on the formation of the iNEMI technology integration groups (TIGs) on Pb-free solders and medical grade component standards. We also know that hermeticity is an issue for the AIMD manufacturers.

So how can NIST best serve these two groups?

1. I believe in general we need more education on hermeticity. A half-day workshop in conjunction with the fall ASTM F04 meeting has been proposed, dealing with hermeticity and leak testing, methods, standard references, etc. I believe that we will need to work through the ASTM because the FDA has a relationship with them and established standards are the only mechanism that the FDA can use to communicate their requirements. But I am concerned about who is our audience for this workshop? Manufacturers, is this a venue with which you can work? Would you prefer a different setting? This probably is not the best situation for educating people from the FDA. Do we need two educational workshops on hermeticity, leak testing, and residual gas analysis? Where should they take place? Are there other pressing educational needs? How should we cover costs?

2. Bob Thomas presented an idea on forming a Task Force that would meet in a pleasant neutral setting with no reports or agendas other than participation. That offer is still on the table if the device manufacturers would like to take him up on it. Do you feel as though your needs are being met with the iNEMI TIGs, and another venue is unnecessary? Do you feel the need for more diverse participation in the iNEMI TIGs?

In conclusion, I would encourage individuals to respond to me and let me know how I can help. I am committed to researching the problems and needs of the AIMD community, and how NIST might best serve that community. I look to you for guidance.

Liz Drexler, drexler@, boulder.nist.gov

Materials Research Engineer, NIST 


\section{Open Comment from Attendees}

We feel that the workshop was successful in getting device manufacturers and the FDA to at least talk to each other about their issues and problems related to measurement methods in evaluating/establishing the reliability of AIMDs. Obviously, follow up work needs to be done and we are definitely interested in actively participating in any forum or workshop that aims to address the industry issues and problems identified in the first workshop.

Please continue to keep us informed of any updates and we look forward to meeting you again soon.

Marcus Ignacio

Edmund Capcelea

Cochlear Limited

14 Mars Road, PO Box 629

Lane Cove NSW 2066

Australia

Here are some quick thoughts:

1. The Medical Device attendees would benefit greatly by having a "Task Force"-like meeting as I described in my presentation. The Minnowbrook Lodge at Blue Mountain Lake is an ideal location and provides a relaxed atmosphere for exchanging ideas. This would be a makers meeting only without any record. All you need is a facilitator and it funds itself. No outside money needed. The purpose of the meeting would be to solve common problems at the physics level. One possibility is to hold it jointly with the October 2006 Moisture and Packaging meeting already in place. There is enough room to host an additional meeting at the same time. Medical attendees would benefit from the discussions on hermeticity, RGA and packaging, but could hold a parallel session for makers only to air their dirty linen. I think that it would work well. The only problem is that it is a year away. An alternative, suggested by John Pernicka is a small island off Florida in January or February to get things started. Makers only with participation by some independents like Ken Rodbell and Celeste.

2. The second need is a seminar for the FDA and NIST people at Gaithersburg to bring the group up-to-date with the hermeticity and RGA lessons learned over 30 years in measurement and manufacturing issues that are directly related to the monitoring of the implant makers. Need three days. Have the speakers in mind. Use training funds to support the attendees.

3. The third need is to work with the FDA assessment organization via a series of seminars and a shadow assessment using QML type auditing techniques. This is really important if you want to get the cooperation of the implant industry. This also should be held at NIST with training funds as the source of support.

4. I am currently proposing a Semiconductor Smart Site@ for the IEEE Reliability Society. 
Using this as the lead demo, the group needs to move ahead in providing a service like this to the implant groups as was discussed at the October Workshop. Will have a business plan that includes revenue from Google to support the expert analysis that will be used in maintaining the Smart Site. More on this later, but getting knowledge on demand to the manufacturers is the way to reduce recalls and cost.

Bob Thomas

Technology Experts Network

104 Cedar St.

Rome, NY 13440 USA 


\section{NIST Technical Publications}

\section{Periodical}

Journal of Research of the National Institute of Standards and Technology-Reports NIST research and development in metrology and related fields of physical science, engineering, applied mathematics, statistics, biotechnology, and information technology. Papers cover a broad range of subjects, with major emphasis on measurement methodology and the basic technology underlying standardization. Also included from time to time are survey articles on topics closely related to the Institute's technical and scientific programs. Issued six times a year.

\section{Nonperiodicals}

Monographs-Major contributions to the technical literature on various subjects related to the Institute's scientific and technical activities.

Handbooks-Recommended codes of engineering and industrial practice (including safety codes) devel- oped in cooperation with interested industries, professional organizations, and regulatory bodies.

Special Publications-Include proceedings of conferences sponsored by NIST, NIST annual reports, and other special publications appropriate to this grouping such as wall charts, pocket cards, and bibliographies.

National Standard Reference Data Series-Provides quantitative data on the physical and chemical properties of materials, compiled from the world's literature and critically evaluated. Developed under a worldwide program coordinated by NIST under the authority of the National Standard Data Act (Public Law 90-396). NOTE: The Journal of Physical and Chemical Reference Data (JPCRD) is published bimonthly for NIST by the American Institute of Physics (AlP). Subscription orders and renewals are available from AIP, P.O. Box 503284, St. Louis, MO 63150-3284.

Building Science Series-Disseminates technical information developed at the Institute on building materials, components, systems, and whole structures. The series presents research results, test methods, and performance criteria related to the structural and environmental functions and the durability and safety characteristics of building elements and systems.

Technical Notes-Studies or reports which are complete in themselves but restrictive in their treatment of a subject. Analogous to monographs but not so comprehensive in scope or definitive in treatment of the subject area. Often serve as a vehicle for final reports of work performed at NIST under the sponsorship of other government agencies. Voluntary Product Standards-Developed under procedures published by the Department of Commerce in Part 10, Title 15, of the Code of Federal Regulations. The standards establish nationally recognized requirements for products, and provide all concerned interests with a basis for common understanding of the characteristics of the products. NIST administers this program in support of the efforts of private-sector standardizing organizations.

Order the following NIST publications-FIPS and NISTIRs-from the National Technical Information Service, Springfield, VA 22161.

Federal Information Processing Standards Publications (FIPS PUB)-Publications in this series collectively constitute the Federal Information Processing Standards Register. The Register serves as the official source of information in the Federal Government regarding standards issued by NIST pursuant to the Federal Property and Administrative Services Act of 1949 as amended, Public Law 89-306 (79 Stat. 1127), and as implemented by Executive Order 11717 (38 FR 12315, dated May 11,1973) and Part 6 of Title 15 CFR (Code of Federal Regulations).

NIST Interagency or Internal Reports (NISTIR)-The series includes interim or final reports on work performed by NIST for outside sponsors (both government and nongovernment). In general, initial distribution is handled by the sponsor; public distribution is handled by sales through the National Technical Information Service, Springfield, VA 22161, in hard copy, electronic media, or microfiche form. NISTIR's may also report results of NIST projects of transitory or limited interest, including those that will be published subsequently in more comprehensive form. 
U.S. Department of Commerce

National Bureau of Standards and Technology

325 Broadway

Boulder, CO 80305-3328

Official Business

Penalty for Private Use $\$ 300$ 